EDITORIAL

Rev Chil Salud Pública 2015;

Vol 19 (1): 125-126

\section{DESASTRES, SEGURIDAD HUMANA Y SALUD}

\author{
DisASTERS, HUMAN SAFETY AND HEALTH
}

Mucha gente se pregunta si los desastres son más frecuentes ahora que en épocas pasadas. Para contestar con exactitud, se requiere entender cuál es el significado de la palabra "desastre". Ello porque la mayoría la asocia al fenómeno destructivo que golpea, destruye o altera la normalidad de una comunidad. Ese, ciertamente, es un error generalizado. Un error que confunde el evento detonante de la crisis: terremoto, temporal, erupción volcánica, aluvión, incendios, etcétera; con el proceso humano, social y económico al que se llega críticamente, cuando estas amenazas de origen natural o de causa humana, hacen emerger vulnerabilidades preexistentes que no pueden ser resueltas y/o enfrentadas con éxito por una sociedad limitada en sus recursos y capacidades. De allí que en los últimos 20 años, las agencias especializadas de Naciones Unidas recomiendan (con limitado éxito) utilizar el término "Desastre de origen natural" o "Desastre de origen antrópico", para referirse a dichos procesos que son, en síntesis, una medida de los factores sociales y modelos de desarrollo en juego. Por lo tanto, estamos hablando de un proceso complejo, más relacionado con los determinantes sociales, con las condiciones en que transcurre la existencia, que con elementos ajenos a la vida cotidiana. Del mismo modo, deben ser vistos como la resultante de un modelo de desarrollo, más que como la falta o ausencia provocada por amenazas y peligros externos.

Estas ideas emergieron con fuerza una vez más, en la reciente Conferencia sobre Seguridad Humana en América Latina, organizada por FLACSO, la Unidad de Seguridad Humana de la ONU y el Ministerio de Relaciones Exteriores de Chile, en abril del 2015. Nuestra participación en el Seminario, en representación de la Escuela de Salud Pública, se centró en "Salud, Seguridad Humana y sus determinantes sociales", y permitió compartir importantes reflexiones con distinguidos panelistas de diferentes organizaciones nacionales e internacionales. La "seguridad humana", tal como ha sido definida por múltiples expertos, tiene entre otras la siguiente definición:

Seguridad de las personas en sus vidas cotidianas, que se alcanza no mediante la defensa militar de las fronteras de un país, sino con la consecución del Desarrollo Humano, es decir, garantizando la capacidad de cada cual para ganarse la vida, satisfacer sus necesidades básicas, valerse por sí mismo y participar en la comunidad de forma libre y segura.

(Karlos Pérez de Armiño y Marta Arezaiga, Universidad del País Vasco) 
Lo interesante de ésta y otras definiciones, es que está centrada en los mismos parámetros que constituyen la médula de una visión renovada de la Salud Pública. El derecho a la supervivencia, a la subsistencia y a una vida con dignidad, son elementos sinérgicos con una visión de Salud Pública que amplía su espectro, centrada en el ser humano como objeto de nuestro interés y preocupación.

\begin{tabular}{ll}
\hline & Los Determinantes Sociales \\
\hline Seguridad Humana & Determinantes Sociales \\
\hline Seguridad Económica & Oportunidades Eduacionales y Laborales \\
Seguridad Alimentaria & Nutrición Segura y Adecuada \\
Seguridad Ambiental & Aire limpio, aguas no contaminadas, saneamiento y espacios verdes. \\
Seguridad Personal & $\begin{array}{l}\text { Protección contra la guerra, las tensiones étnicas, la delincuencia, violencia de } \\
\text { pandillas, violaciones, violencia doméstica, maltrato de menores, suicidios, } \\
\text { drogadicción, etc. }\end{array}$ \\
Seguridad de la Comunidad & Modos de vida saludables y sólidas redes sociales y familiares \\
Seguridad Política & Protección de los Derechos Humanos \\
\hline
\end{tabular}

Tratemos de responder ahora la pregunta inicial: ¿Son los 'desastres' más frecuentes en la actualidad que en el pasado?

Las cifras de mortalidad, daño al patrimonio, impacto ambiental y otros indicadores muestran en los últimos 20 años algunos valores destacables: La cantidad de desastres de origen geofísico (sismos, tsunamis, volcanismo, etc.), parece haberse mantenido en número de eventos. Sin embargo, los desastres asociados a fenómenos hidrometeorológicos relacionados con el cambio climático, han aumentado dramáticamente la frecuencia de huracanes, inundaciones y sequías, representando más del $70 \%$ de los escenarios destructivos vividos, con un aumento del $87 \%$ desde fines de la década de los ochenta.

De acuerdo con el último reporte de Munich Re y Swiss Re, las cifras de mortalidad han sido reducidas en términos globales en la última década. Ello parece deberse a mejores sistemas de alerta temprana en diferentes regiones del mundo. Sin embargo, las pérdidas económicas reportadas por desastres de origen natural y antrópico, en 2014, ascendían a 113 mil millones de dólares. Solamente un tercio de dichas pérdidas estaban aseguradas. Por tanto, en términos de transferencia de riesgos, la humanidad está lejos de hacer progresos. Por otra parte, muchos expertos sostienen que estamos incrementando el riesgo en forma imprudente debido a nuestro mal manejo del medio natural.

En los recientes eventos catastróficos vividos por nuestro país: 27F, incendios de los cerros de Valparaíso, aluvión de Copiapó, erupción del volcán Calbuco (en muchos de estos casos, asociados a grandes inversiones económicas que generan empleo, pero carentes de seguridad), los mayores costos en calidad de vida reducida y destrucción de patrimonio personal y colectivoambiental, se expresan en sectores pobres y marginales. Durante los últimos 20 años, en los países en desarrollo han ocurrido tres veces más desastres de origen natural que en los países desarrollados. La ocupación habitacional de sitios de alto riesgo, tales como quebradas, cauces de ríos, borde costero, faldeos volcánicos, entre otros, no hacen sino confirmar que somos creadores de nuevas vulnerabilidades y riesgos intolerables, desconociendo nuestra historia de desastres recurrentes y las lecciones de una naturaleza que no olvida. 